\title{
The Argentine Approach to Radiation Safety: Its Ethical Basis
}

\author{
Abel J. González \\ Autoridad Regulatoria Nuclear (ARN), Avenida Del Libertador 8250, 1429 Buenos Aires, Argentina \\ Correspondence should be addressed to Abel J. González, agonzalez@arn.gob.ar
}

Received 3 September 2010; Accepted 8 December 2010

Academic Editor: Juan Ferreri

Copyright ( 2011 Abel J. González. This is an open access article distributed under the Creative Commons Attribution License, which permits unrestricted use, distribution, and reproduction in any medium, provided the original work is properly cited.

\begin{abstract}
The ethical bases of Argentina's radiation safety approach are reviewed. The applied principles are those recommended and established internationally, namely: the principle of justification of decisions that alters the radiation exposure situation; the principle of optimization of protection and safety; the principle of individual protection for restricting possible inequitable outcomes of optimized safety; and the implicit principle of intergenerational prudence for protection future generations and the habitat. The principles are compared vis-à-vis the prevalent ethical doctrines: justification vis-à-vis teleology; optimization vis-àvis utilitarianism; individual protection vis-à-vis deontology; and, intergenerational prudence vis-à-vis aretaicism (or virtuosity). The application of the principles and their ethics in Argentina is analysed. These principles are applied to ALL exposure to radiation harm; namely, to exposures to actual doses and to exposures to actual risk and potential doses, including those related to the safety of nuclear installations, and they are harmonized and applied in conjunction. It is concluded that building a bridge among all available ethical doctrines and applying it to radiation safety against actual doses and actual risk and potential doses is at the roots of the successful nuclear regulatory experience in Argentina.
\end{abstract}

\section{Introducion}

The purpose of this paper is to review the ethical basis of the radiation safety approach used in Argentina. The term radiation safety is used holistically to denote whatever is done to prevent or limit injury, damage, or simply risk from radiation exposure. It encompasses the traditional concept of radiological protection, the less precise notion of nuclear safety, and the new creation confusedly named "radiological and nuclear security". The term exposure is used generically to mean the state of being exposed to radiation harm, be it either those delivering actual dose or those delivering actual risk and a potential to incur doses. The paper is also aimed at revitalizing that ethical basis vis-à-vis both the new 2007 recommendations of the International Commission on Radiological Protection issued as ICRP Publication 103 [1] and the international Fundamental Safety Principles issued by the International Atomic Energy Agency [2]. The latter is the primary international safety standard underpinning international safety obligations that have been undertaken by Argentina. The ICRP recommendations propose a radiation protection paradigm or model for ensuring that human and their habitat are properly protected against the potential harmful effects of radiation exposure, which serves as the basis for the international safety principles and also for the Argentinean radiation safety standards.

\section{Antecedents}

Argentina's radiation safety experts have been (and continue to be) very keen in exploring and reassessing the rules and standards governing their professional conduct. They have had an unusual curiosity to self-inspect whether they hold a right behaviour and what are the set of principles for self-ensuring that such behaviour is right. This interest of self-appraisal of conduct correlates with the ancient Greek notion of ethics ( $\eta \theta_{\iota \iota}$ from Uthos "natural disposition"). (The concept of ethics was formerly synonymous to the Latin moral (moralis, from mos, mor- "custom") and to the AngloSaxon behaviour (from be- + have in the sense "bear oneself in a particular way").) Ethics is the fundamental earliest concept for judging human actions, which on radiation safety has transcended as the moral set of values sustaining the professional conduct on radiation safety actions and the rules and principles that ought to govern those actions. 
The ethical basis of radiological protection was early recognized by the discipline's fathers, and particularly by the de facto founder of the discipline in Argentina, Dan J. Beninson. Taylor, who was one of the world earlier initiators of radiological protection, already in 1957 stated that "Radiation protection is not only a matter for science. It is a problem of philosophy, and morality, and the utmost wisdom." [3]. A particular sudden increase in interest on the topic arose after "societal" recommendations in ICRP Publication 9 [4] (which were refined in ICRP Publication 22 [5] and finally elaborated in ICRP Publications 26 and $60[6,7])$ that "doses be kept as low as reasonably achievable (ALARA), economic and social considerations being taken into account".

Around the 70s, a number of influential radiation protection papers touched the issue of radiological protection ethics. These include those of former ICRP Presidents Bo Lindell, 1973 IRPA Sievert Lecture on Radiation and Man [8], Taylor again in his 1980 Sievert Lecture on Some NonScientific Influences on Radiation Protection Standards and Practice [9], Lindell again in his 1988 NCRP Lauriston S. Taylor Lecture on How Safe is Safe Enough [10], and, finally, the seminal 1996 Beninson's Sievert Lecture on Risk of Radiation at Low Doses [11].

The subject was also specifically addressed by the former Scientific Secretary of the United Nations Scientific Committee on the effects of atomic radiation (UNSCEAR), Silini, in the 1992 Sievert Lecture [12]. By then, a great interest on the issue arose in Nordic countries, and an influential international workshop was held by the Swedish Radiation Protection Institute in 2000 [13]. Thus, the last decades of the XX century become decisive for the evolution radiation protection ethics: an interesting saga well described in Lindell's leading books on this historical period [14-16]

After the 2007 ICRP Recommendations were issued, there were a number of ethics-related initiatives by the Nuclear Energy Agency of OECD (NEA-OECD), including in-depth discussions of how science and social values are taken into account in the formation of radiation protection policy and regulatory judgments, which took place at NEA-OECD Science and Values in Radiological Protection Workshops held in Finland in January 2008 [17] and Vaulx de Cernay, France, on November 2009 [18].

The 2007 ICRP Recommendations ascertain a number of basic principles than will govern radiation protection in the forthcoming future. While the recommendations were in preparation, the former ICRP Chairman, Clarke, suggested proposals for strengthening the individual-related principles of the ICRP recommended system of protection [19-21]. However, some people felt that the social-related ethical basis of radiation protection could be jeopardized and reflected their concerns in some papers and in a seminal anthology on ethics and radiological protection [22]. However, as this paper will demonstrate, the concerns were unfounded: the ethical framework under which the ICRP principles were based not only continues unchallenged but has been strengthened and the ethical principles of Argentina's radiation safety will continue to be robust and based on those principles.

\section{Argentine Approach to Radiation Safety}

In Argentina, the basic principles for radiation safety are based on the ICRP recommendations and are also fully tailored to the fundamentals of the international safety regime being built under the aegis of the IAEA. The current Argentine basic radiation safety standards [23] declare as its objective "achieving an appropriate level of protection of individuals against the harmful effects of ionizing radiation and safety of radiation sources" and fully follow the ICRP principles (as practically all national and international standards do).

However, Argentine regulations are unique in that these basic principles have been extended to the so-called "nuclear safety" standards, which are based on the same principles than those of radiation safety standards. The basis of nuclear safety in Argentina is governed by a standard on radiological criteria relating to accidents [24], which establishes the general conditions that must be met in the design, to prevent the occurrence of accidents and mitigate radiological consequences if they occur. The basic criteria are that any potential accidental sequence with radiological consequences to the public must have a convolution of annual probability of occurrence and potential dose that might deliver that is compatible with the ICRP system of dose limitation.

3.1. The Basic Principles. The basic principles developed by ICRP over the years and adopted in Argentina continue to be regarded as the fundamental basis for a system of radiation safety. These principles can be formulated as follows.

(i) The principle of justification implies that any decision that alters the radiation exposure situation should do more good than harm-meaning that by introducing new radiation sources or by intervening for reducing existing doses or the risk of potential doses, sufficient individual or societal benefit should be achieved to offset the detriment such actions may cause.

(ii) The principle of optimization implies that the likelihood of incurring exposures, the number of people exposed, and the magnitude of their individual doses and risks should all be kept as low as reasonably achievable, taking into account economic and societal factors-meaning that the level of safety should be the best under the prevailing circumstances maximizing the margin of benefit over harm.

(iii) The principle of individual protection implies that the total dose and risk incurred by any individual should be restricted-meaning that severely inequitable outcomes of optimized safety should be prevented by restrictions on individual doses (implemented throughout individualrelated dose and risk limits and source-related dose and risk constraints and reference levels, see hereinafter).

Another principle that is not specifically declared as such by ICRP, but which is implicitly referred to in many statements and underlines most of the ICRP recommendations, international standards, and also Argentine regulations, could be formulated as follows.

(iv) The principle of intergenerational prudence, which extends safety to all humanity, regardless of where and when they live, and implies that all humans, present and future, shall be afforded with a level of safety that is not weaker than 
the level provided to those populations causing the safety needs.

International safety standards have mutatis mutandi adopted the ICRP protection principles converting them in a de facto universal undertaking because these standards are referred to, directly or indirectly, in relevant international safety conventions (see, e.g., $[25,26])$. Argentina, as party of these international undertakings, has made them part of the Argentine legislation and therefore they are legally binding.

The formulation of some of the international Fundamental Safety Principles is based on the ICRP principles. The current Fundamental Safety Principles are ten, namely, responsibility for safety; role of government; leadership and management for safety; justification of facilities and activities; optimization of protection; limitation of risks to individuals; protection of present and future generations; prevention of accidents; emergency preparedness and response; protective actions to reduce existing or unregulated radiation risks. Four of them were extracted from the ICRP recommendations and are formulated as follows: justification of facilities and activities (facilities and activities that give rise to radiation risks must yield an overall benefit); optimization of protection (protection must be optimized to provide the highest level of safety that can reasonably be achieved; limitation of risks to individuals (measures for controlling radiation risks must ensure that no individual bears an unacceptable risk of harm); protection of present and future generations (people and the environment, present and future, must be protected against radiation risks.)

3.2. Uniqueness of the Approach: Extension to Nuclear Safety. Proposals for safety criteria based on a probabilistic approach founded on the underlying principles of the dose limitation system used for radiological protection purposes were very early suggested by Argentina [27]. The basic proposal was to use the available probabilistic tools, such as event and fault trees, for a priori overall safety analyses of nuclear installations. A comparison could, therefore, be performed between the probability of occurrence of a hypothetical chain of events leading to an unexpected human exposure, along with its consequences-in terms of doses incurredand a probabilistic regulatory criterion. The relevant safety authorities would then be able to judge the safety level of the plant on the basis of a rational approach sharing the same principles of radiological protection.

It must be emphasized that the Argentina proposals for using probabilistic safety criteria were never aimed at performing a posteriori "confirmatory" studies of the risk of nuclear power. Rather, they aim to check a priori that the prevention of nuclear accidents was coherent and consistent with the criteria and principles derived from the system of dose limitation used for radiological protection purposes. In practice this would be achieved by enforcing mandatory probabilistic safety objectives and by obliging applicants to perform probabilistic safety analyses of the installations and confirm that those objectives were met.

I should also underline that a priori probabilistic analysis allows firmly grounded anticipation, when there is frequency data that allow classical statistical treatment, and (with the help of Bayes' theorem) solidly founded inference when only professional judgment is available.

Thus, at a very early time, the Argentine authorities issued a probabilistic safety criterion that served as a basis for the current regulatory system. The main criterion was issued as Norm Number 3.1.3., "Criterios radiológicos relativos a accidentes" (Radiological criteria in relation to accidents), [28] and further clarified by Norm Number 3.2.2., "Análisis de fallas para la evaluación de riesgos" (Failure analysis for risk evaluation) [29], and it was presented at various international meetings $[30,31]$. These norms were later endorsed by the ARN of Argentina and formalized in the current normative for nuclear safety [24] for the licensing of nuclear installations. The aim of the criterion was requiring applicants for a nuclear installation license to identify the failure sequences which, in case of occurrence, will deliver a radiation dose to members of the public and make their probability of occurrence sufficiently low to be coherent and consistent with the radiological protection principles. The probability of occurrence of each failure sequence, as well as the corresponding activity of released radionuclides, should be assessed by using event and fault trees, while taking into account the following criteria: (i) the failure analysis shall systematically encompass all foreseeable failures and failure sequences, including the common-mode failures, the failure combinations, and the situations exceeding the design basis (failure in this context means an aleatory event preventing a component from performing its safety function, as well as any other event which may additionally occur as a necessary consequence of such deficiency; failure sequence, on the other hand, means a sequential series of failures which can, although not necessarily, occur after an initiating event); (ii) a failure or a failure sequence may be selected as representative of a group of failures or of failure sequences (in such a case, the failure or failure sequence to be selected from the group shall be that delivering the worst consequences and the analysis shall take into account the sum of the probabilities of the failure or failure sequences in the group); (iii) the analysis shall consider that a protection function may have lost operativeness either before the occurrence of the failure or of the failure sequence or as a result of such occurrence; (iv) the analyses of failures, of failure sequences, or of any part thereof shall be based on experimental data as far as it is possible (if this cannot be done, the valuation methods must be validated through appropriate tests); (v) the levels of failure rate assigned to the safe-related components, in the evaluation of the failure probability of systems, shall be justified; in case that justifiable values were not available for some of the components, the applicant shall use levels of failure rate prescribed by the licensing authority (if a given failure rate is justified on the basis of quality assurance, this must be specified in detail); (vi) the failure analyses shall consider the maintenance and testing procedures and the time interval between successive maintenance and testing actions; (vii) failure rates postulated for human actions shall be justified taking into account the complexity of the task, the stress involved, and any other factors which might influence that failure rate. 
Thus, the doses on a critical group of people, which would result from the release of radionuclides due to a failure or failure sequence, shall be assessed by accepted methods. (The assessment shall take into account the meteorological conditions of dispersion at the site and their probabilities, but it shall not take into account the eventual application of countermeasures, even if they are forecasted in emergency planning.) The annual probability of occurrence of any failure sequence, when plotted as a function of the resulting effective dose, shall result in compliance with a criterion that is coherent and consistent with the principles of radiological protection enounced above. The implicit basic safety goal is a risk limit derived from the dose limitation system used for radiological protection purposes, which-as seen before-includes four principles: two of them are source related (e.g., justification and optimization) and the other two are individual related (e.g., individual limitation and intergenerational protection). These latter principles entail that the risk committed by individual sources should be low enough as to be automatically disregarded. The currently recommended dose limit of $1 \mathrm{mSv}$ per year implies an annual risk limit of around $10^{-5}$ for any individual, even for the highest exposed one, as a result of performing all practices involving radiation exposure.

As it would be discussed hereinafter, since the dose limits relate to individuals, appropriate constraints for individual doses should be selected for each source of exposure. The dose constraint must be sufficiently lower than the relevant dose limit, so as to prevent individual exposure due to several sources from exceeding such limit. In Argentina, a regulation controlling the release of radioactive effluents from nuclear power plants had been established at the time imposing a dose constraint of $0.3 \mathrm{mSv}$ per year [32]. (Optimization was always an additional mandatory requirement in the Argentine regulations, so that - in practical cases - the actual highest individual dose has resulted to be far lower than the constraint.) Therefore, the de facto annual limit of individual risk would become lower than the limit of around $10^{-5}$. On the basis of the above limit and taking into account the uncertainties usually involved in probabilistic safety assessments, the Argentine authority did consider that an annual risk limit for accidental exposures from nuclear installations should not exceed an order of $10^{-6}$. This would be consistent with the principles involved in the currently enforced system of dose limitation. Accidental exposures may arise from a theoretically infinite number of accidental sequences, each one having a given probability of occurrence and delivering a given expected dose to the most exposed individual. The actual risk incurred by this individual will then result from the integration of the tail distribution of doses (i.e., the complement of the probability function of doses) times the probability of death provided the dose is incurred. The safety constraint should therefore be that the value of this integral be lower than $10^{-6}$ per annum.

The assessment of all possible accidental sequences involving radiation exposure is extremely difficult and practically impossible. Therefore, the Argentine authority is satisfied if only ten of the most relevant sequences are identified and has assigned them an annual risk limit of $10^{-7}$.

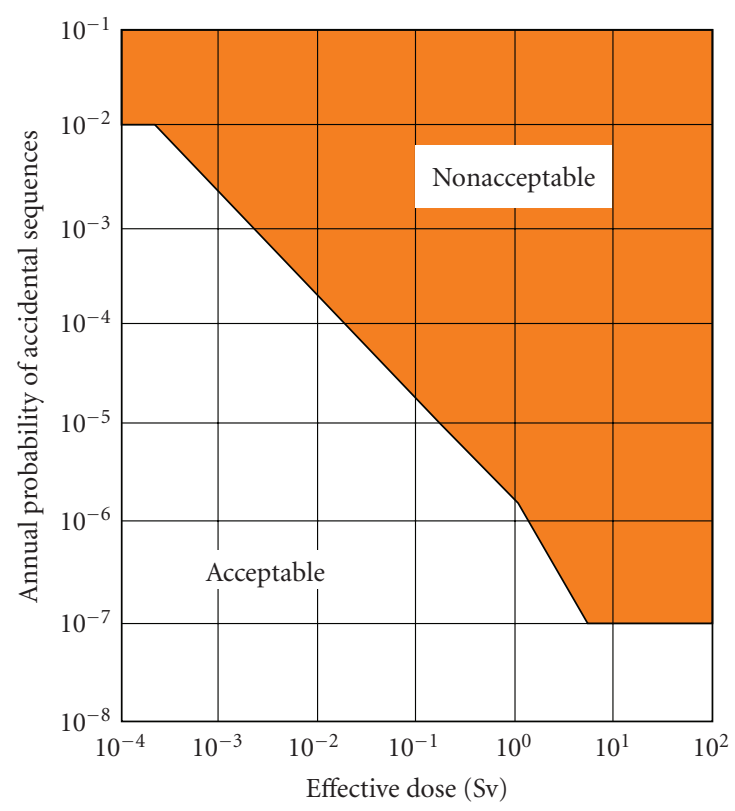

FIgURE 1: The criterion curve for the public.

Since each sequence may result in different doses, a criterion curve was adopted, which is a relationship between the annual probability of sequence occurrence and the expected individual dose, each point of the curve representing a constant level of risk. The criterion curve enforced by the Argentine authority is shown in Figure 1. (Failure of a point to be under the criterion curve does not necessarily mean that the risk constraint is not met, because even in this case, the integral of the tail distribution could be lower than $10^{-6}$ annum.)

The logic behind the criterion curve is as follows. For the range of doses from which only stochastic effects of radiation can be incurred, the criterion curve must show a constant, negative, $45^{\circ}$ slope in a-log annual probability versus log individual dose-coordinate axis plane. This would ensure that the annual probability of incurring the dose times the probability of death provided the dose is incurred (the latter being in the order of $10^{-2}$ per Sv) will be kept constant. One of the coordinate points in this part of the curve would obviously be the following: annual probability: $\sim 10^{-7}$ annum $^{-1}$; individual dose: $1 \mathrm{~Sv}$, because the product $10^{-5}$ annum $^{-1} \times 1 \mathrm{~Sv} \times 10^{-2} \mathrm{~Sv}^{-1}$ results in an annual risk of $10^{-7}$ annum $^{-1}$. In the dose range where nonstochastic effects of radiation may occur (i.e., for individual doses higher than around $1 \mathrm{~Sv}$ ), the slope of the curve should increase, in order to take into account the higher risks of death at these levels of dose. For doses higher than approximately $6 \mathrm{~Sv}$, the probability of death approaches unity. From this level to higher doses, the criterion curve should remain constant at an annual probability of $10^{-7}$ (because the exposed individual would inevitably die regardless the level of the dose). Between the coordinate points defined by annual probability: $10^{-5}$ annum ${ }^{-1}$; individual dose: $1 \mathrm{~Sv}$ and annual probability: $10^{-7}$ annum ${ }^{-1}$; individual dose: $6 \mathrm{~Sv}$, the criterion curve should show a shape similar to that of the 
relationship between the individual dose and the frequency of death (which, at that range, is approximately S-shaped but, for the sake of simplification, the authority has decided to approximate these two points by means of a linear-shaped relationship). Finally, the criterion curve has been truncated at an annual probability level of $10^{-2}$, because the occurrence of incidents having a higher annual probability (regardless the dose) is unacceptable for the authority.

It should be emphasized that the criterion curve is individual related; that is, it is intended to limit the risk rate on the individual incurring the highest risk but does not take into account the overall expected impact from accidental situations. The criterion assures a level of safety which is sufficient to ensure that an individual risk constraint, compatible with the philosophy of the dose limitation system, will not be exceeded. It fails, however, to answer positively the old question of the safety engineers, that is, is such safety level safe enough as to preclude further safety improvements? An installation complying with the criterion would be equally considered whether it is imposing risks (lower than the "acceptable" one) to few individuals or if many individuals would incur such risks. If an accident does occur, however, the overall radiological impact will be very different in each case, suggesting that the overall safety level might be lower in the second than in the first one. Optimization may require further safety improvements in the second case. But is this really necessary, providing the individual-related criterion is met? if so, on what basis can optimization be implemented? The answers to these questions would allow for complementing the probabilistic criterion based on individual risk considerations alone.

The ICRP recommended the use of the concept of radiation detriment, namely, the mathematical expectation of harm, to quantify the impact from a source of radiation exposure. The detriment is an extensive quantity that estimates the combined impact of deleterious effects resulting from exposure to a given radiation source. It is defined as the expectation of the harm to be incurred, taking into account the expected frequency and severity of each type of deleterious effect. The detriment incurred by one individual receiving a dose in the range of stochastic effects is proportional to the effective dose incurred, the proportionality factor being the probability that the individual will incur a deleterious effect as a result of the exposure. Therefore, in cases of actual exposures to low levels of dose, the total detriment is proportional to the sum of all individualeffective doses incurred, that is, is proportional to the collective dose commitment (this latter quantity results from the time integration of the collective dose rate, which, in turn, results from the integral of the population spectrum in terms of effective dose rate incurred). It was therefore tempting to use a similar concept for measuring the expected impact from accidental exposures. [33]

For potential accidental exposures, the concept of detriment may keep its theoretical meaning although it would become a quantity of a second order of stochasticity. In such case, the probability of a given exposure, that is, the combined probabilities of both, an accidental release and an environmental condition (dispersion, deposition), should be introduced in the formulation and integrated over all possibilities. Then, if low doses were expected, the detriment should be proportional to the resulting mathematical expectation of the collective dose commitment. For higher doses, another component of the detriment should be added in order to take into account the nonstochastic effects of radiation. This idea of using the detriment of a second order of stochasticity, and the related mathematical expectation of collective dose commitment, for quantifying the impact from accidental exposures is really appealing, as the concept would allow for optimizing safety, increasing it to a sufficiently high level that further improvement would not be worthwhile taking into account both the benefits achieved in terms of expected collective dose commitment reduction and the cost of obtaining such reduction. However, unfortunately, it was demonstrated [34] that, at very low probabilities, the detriment will lose its usefulness as a basis for decisionmaking. In fact, in such cases the standard deviation of the result may be orders of magnitude higher than the actual expectation and the coefficient of variability would become very large. The detriment is then no longer a central measure of the distribution of harm, and, in addition, the uncertainty of the detriment becomes too large to make it meaningful, even if the probability as such could be estimated by safety assessments with an accurate degree of certainty. At very low failure probabilities, the inherent uncertainty of the product of probability and consequences makes the use of this quantity rather doubtful. For these reasons, for potential accidental exposures the principle of justification and optimization is implemented in a less quantitative manner. The value assigned to the variables follows a utility function of probability and consequence. The utility function usually gives more weight to larger accidents than would be implied by the direct product probability times consequence.

In sum, the Argentine approach to radiation safety has a uniqueness: its coherence and consistency vis-à-vis both actual radiological situations and potential nuclear safety situations. This exceptionality is at the basis of its claim that it is based on a common ethical approach.

3.3. Ethical Obligations. In Argentina, ethics in public functions is imposed by law. The 25188 Act, "Law of Civil Service Ethics" [35], and its amending regulations regulate the ethical behavior involved in public service and encompass radiation safety regulators. This ethics law provides a set of duties, prohibitions, and incompatibilities applicable, without exception, to all public servants at all levels and hierarchies, permanently or temporarily, by popular election, appointment directly by competition, or any other legal means, extending them to all judges, officers, and employees of the State. Thus, the Argentine ARN issued its own Code of Ethics as by [36], which is fully coherent and consistent with the Code of Ethics of the International Radiation Protection Association (IRPA) [37] aimed at aiding "radiation protection practitioners in maintaining a professional level of ethical conduct related to radiation protection." One interesting requirement of the Argentine Code of Ethics is related to interrelations with other groups of interest 
and states that "engagement with stakeholders should be based on respect for their rights and seek solutions that address their interests, while maintaining consistency with regulatory objectives and the welfare of society." Argentina has also adhered to the efforts of the International Atomic Energy Agency (IAEA) for addressing the difficult issues of ethical considerations in protecting the environment from the effects of ionizing radiation $[38,39]$ and establishing a code of ethics for nuclear operating organizations [40].

\section{The Radiation Safety Principles Vis-À-Vis Ethical Doctrines}

4.1. Ethical Doctrines. Ethics has a long historical evolution mainly based on religious thinking and philosophical speculation. Over time it is converging in a limited number of doctrines. Four fundamental ethical doctrines are introduced although sketchily and schematically, namely, in a simplistic or formulaic character. The intention is not to describe these doctrines for the benefit of ethicists but for radiation protectionists and other professionals related to nuclear and radiological safety. The excessive schematization may be ignored because the purpose of the paper is limited to provide elementary ethical basis to the four principles of radiation safety, justification, optimization, limitation, and prudence. The ethical doctrines to de discussed are the following (in arbitrary order):

(i) the teleological ethics (or ethics of consequence), which is expressed with the aphorism "The ends justify the means,"

(ii) the utilitarian ethics (or ethics of efficacy), which is expressed with the aphorism "The greatest good for the greatest number of people,"

(iii) the deontological ethics (or the ethics of duty), which is expressed with the aphorism "One should do unto others as they would have done unto them" (or with the religious dogma "God commandment may be summed up in this one rule: care for your neighbour as yourself"),

(iv) the ethics of virtue (or aretaic ethics), which is expressed with the aphorism "be charitable and benevolent unto others as you would be done by."

All these ethical doctrines are fundamentally anthropocentric. Teleological and utilitarian ethics belong to a family of "social-oriented" ethics; deontological and aretaic ethics belong to a family of "individual-oriented" ethics. In relation to protection, namely, to keeping humans safe from harm or injury, teleological and utilitarian ethics aim at the right principles for protecting society as a whole, while deontological and virtue ethics are more focused on individual protection.

4.1.1. Teleological (or Consequentialistic) Ethics (from the Greek Telos, "End"; Logos, "Science"). It is usually referred to as consequentialism, because it holds that the consequences of a particular action form the basis for any valid moral judgment about that action. It is rooted in ancient teleological thinkers but flourished in the renascence, when Nicolò, in his book "The Prince," argued that rulers (i.e., modern decision makers) ought to be consequentialists [41]. Safetyrelated consequentialism would therefore hold that the ends or consequences of a safety-related action should determine whether such action is good or evil. Thus, it is concerned with overall outcomes or consequences of human safetyrelated actions, which would be morally right if it produces a good outcome or consequence-namely, more absolute good than absolute harm.

4.1.2. Utilitarian Ethics. It is based upon the principle of maximization of the good. While rooted Epicurus' basic ethical guideline emphasized minimizing harm and maximizing good, utilitarianism is a rather modern evolution of absolute consequentialism. It was articulated in the XIX Century seminal writings of Bentham [42] and Mill [43]. Unfortunately utilitarianism has been distorted by associating it to pure hedonism, namely, it has been perceived as consequentialist ethical theory that endorses hedonism as a theory of value. However, the basic creed of utilitarianism holds that actions are right in proportion as they tend to maximize goodness and wrong as they do not do it, and its ultimate purpose should not necessarily be considered either hedonistic or masochist but simply a morally correct action. Utilitarianism is also known as the maximum goodness principle. Utility, the good to be maximized, has been defined as the satisfaction of preferences, with maximum outcome being of ultimate importance. By definition, therefore, utilitarianism requires a differential approach for balancing the various options for actions. Safety-related utilitarianism would therefore claim that the moral worth of any protective action is determined solely by its contribution to overall utility, that is, the action should lead to the best outcome as summed among all people. It may thus be considered to be a differential form of safety-related decisions by consequentialism, meaning that the moral worth of any protective action is determined by the maximization of the differential positive outcomes it brings about.

\subsubsection{Deontological Ethics (from the Greek $\delta$ Éov, Deon,} Duty, and $\lambda$ oyía, Logos Science). It determines goodness or rightness from examining the actions in their own duty value rather than their consequences or utility [44]. Deontology is rooted on ancient philosophies and religious thinking, particularly those from monotheistic faiths. It benefited from the immense contribution of the philosophers Kant and Ladd [45], who argued that to act in the morally right way, people must act from duty and that it was not the consequences or utility of actions that make them right or wrong. He had to deal with the problems created by duty "in extremis" that he summarized in a famous hyperbole: "better the whole people should perish than that injustice be done." A plausible response to this hyperbolic dilemma is what is usually called "threshold deontology," which holds that deontological norms govern up to a point despite adverse consequences or utility; but when these become so dire that 
they cross the stipulated threshold, teleology and utility take over [46]. Clusters of deontological doctrines converge in what is usually termed the "Divine Command theory," which dogmatically states that an action should be right if God has decreed that it is right [47]. Abrahamic religions consider that humans are mirrors of God (Gen. 1:26, 27; Gen. 9:6) (Hebrew: צֶּל אֶלהִים ;zelem elohim, literally "image of God," often described in Latin as Imago Dei), which is a concept that asserts that human beings are created in God's image and therefore have inherent value independent of their utility or function (this is particularly emphatic in Christianity (Rom. 8:29; I Cor. 11:7; II Cor. 3:18; II Cor. 4:4; Col. 1:15; Col. 3:10; James 3:9), but not in Islam where man seems not be considered to be made in the image of God (Koran 42:11)). Not surprisingly, deontological Western ethics would therefore evolve into an anthropocentric and individualist approach. Safety-related deontology would therefore just look at safety-related moral duties and consider that a protective action is right if it is dutiful for the individuals concerned, even if it produces a negative overall consequence or utility. However, safety-related deontology shall necessarily be a threshold deontology, arguing that, for protecting in the morally right way, the protector must act from duty imposing limits up to a point: the highest good must be the good individual safety in itself up to the point where it becomes individually irrelevant. Individual safety would then be "good in itself" when it is intrinsically good for the individual being protected regardless of whether it is good for society as a whole or not. Moreover, the individual being protected is an actual individual contemporaneous to the protective action rather than an idealized individual that may or may not exist in reality.

4.1.4. Virtue (Aretaic) Ethics. It emphasizes the virtues, or moral character of actions, in contrast to their consequences, utility or duties. It claims that such moral character should be the focal point for judging the ethics of the action. Virtue ethics' founding fathers are Plato and, more particularly, Aristotle (it has even more ancient roots in Chinese philosophy), and it persisted as the dominant approach in Western moral philosophy until at least the Enlightenment and has reemerged in the middle of the last century. Its key concepts include arête (from Greek: $\dot{\alpha} \rho \varepsilon \tau \dot{\eta})$ ), that is, excellence or virtue, eudaimonia (from Greek: $\varepsilon \dot{v} \delta \alpha \iota \mu \nu i \alpha$ ), that is, the old oriental principle of flourishing, and fundamentally phronesis (from Greek: $\varphi \rho o ́ v \eta \sigma \iota \varsigma$ ), that is, the practical or moral wisdom that derives from Aristotle's Nicomachean Ethics and which can be defined as the virtue of practical thought, sometimes translated as practical wisdom, prudence, and precaution. [48-55]. Safety-related virtue would therefore hold that, on the one hand, safety-related deontological doctrines are selfish individualist and, on the other hand, consequentialistic and utilitarian doctrines totally disregard the development and importance of moral character. Accordingly, solely individual concerns and safety-related consequences and utilities would in themselves have no ethical content, unless it had been provided by a virtue such as benevolent responsibility toward our descendants.
Therefore safety by virtue will be mainly equalitarian not only towards the contemporaries of the protectors but also to the generations to come. Thus, safety-related virtue ethics fundamentally leads to sustainable intergenerational safety values.

4.1.5. Moral Dilemmas on Safety Decisions. It may result from responding to the imperative or one or another ethics or all of them. This brings about moral conflict, when a safety decision maker (or protector) may regard itself as having moral reasons to act according to two different ethics but doing both actions is not possible. The crucial features of these moral dilemmas are that the protector is required to implement each of the two or more protective actions, and it can implement each of the actions but it cannot do both (or all) of the actions. The protector thus seems condemned to moral failure; no matter what it does, it will do something wrong (or fail to do something that it ought to do). As the paper will describe, safety-related moral dilemmas have been resolved in radiation safety through the integration into a common system of radiation safety principles that are rooted in solid ethical approaches.

4.2. Justification and Teleology. The foundation of the justification principle on teleological ethics is self-evident. The justification principle holds that any decision that alters the radiation exposure situation should do more good than harm and corresponds directly to the teleological consequentialistic doctrine holding that protective choices, acts, and/or intentions are to be morally assessed solely by the states of affairs they bring about.(In radiation protection parlance, justification is specifically the process of determining whether either (i) a planned activity involving radiation is, overall, beneficial, that is, whether the benefits to individuals and to society from introducing or continuing the activity outweigh the harm (including radiation detriment) resulting from the activity or (ii) a proposed remedial action in an emergency or existing exposure situation is likely, overall, to be beneficial, that is, whether the benefits to individuals and to society (including the reduction in radiation detriment) from introducing or continuing the remedial action outweigh its cost and any harm or damage it causes.)

However, it should be expected that justification and teleology specify the states of affairs that are intrinsically valuable: the good. They then would be in a position to assert the safety choices that, altering the radiation exposure situation, increase the good, that is bring about more of it, and therefore are the choices that it is morally right to make and to execute. (The good in that sense is said to be prior to the dutiful right.) Professionals in teleology and in radiation safety can and probably will differ widely in terms of specifying the good following a decision that alters the radiation exposure situation. Some may be monists and deny the existence of a distinction or duality about the good and generically identify it with "welfare," but others may be pluralists and recognize more than one ultimate teleological principle, for instance, more than the principle 
of justification per se. As it will be seen, radiation safety has ascribed to the pluralistic concept, actually de facto endorsing the principle that how the good is distributed among persons (or all sentient beings) is itself partly constitutive of the good. That is, radiation safety professionals are egalitarians rather than conventional consequentialists who merely add each person's share of the good to achieve the good proper.

In Argentina, like in other countries, there may be personal differences about what the good consists, but there is an agreement that the morally right choices among those that alter the radiation exposure situation are those that increase the good. Moreover, it is generally considered that the good should be "agent-neutral", namely, that valuable states of affairs are states of affairs that all agents have reason to achieve.

It is to be noted that applying justification, and therefore teleological ethics, to decide on actions altering the radiation exposure situation is being done within a self-critique attitude for a number of reasons.

(i) For its extreme demandingness, as there is no realm of moral permissions, no realm of going beyond one's moral duty (supererogation), no realm of moral indifference. All actions are seemingly either required or forbidden, and the approach might be deemed profoundly alienating and perhaps self-effacing safety moral.

(ii) For what it seemingly permits-or, more accurately, requires. If wrongly interpreted, it might be seen to demand (and thus, of course, permit) that innocents be killed because of lack of safety or deprived of material goods because of excessive safety that may produce greater benefits for others. Consequencesand only consequences - from deciding actions altering the radiation exposure situation can conceivably justify any kind of act, no matter how harmful it is to some.

(iii) For the little or no guidance it gives to persons' practical reasoning, because the consequences of any action stretch into the distant future, making them essentially unknowable.

However, radiation safety professionals effectively took into account those seemingly valid critiques to pure teleology and corrected them. In fact, one problem with justification is that when "balancing" the good and the evil, these are not confined to those good and evil associated with radiation exposure-they include other no radiation-related benefits and detriments arising from the activity. Pure teleological justification thus goes far beyond the scope of radiation safety. It is for these reasons that in Argentina justification requires that the net radiation-related benefit be positive, and therefore the teleology becomes de facto radiation-related differential, expressing a subtle different teleology. The logic is clear: the search for the best of all the available alternatives is a task beyond the responsibility of radiation safety professionals; their teleological remit is confined to ensure a positive net radiation-related benefit. But in addition, to respond to the other criticism requires additional principles based on different ethics. One of them is to search for the best of all the available safety options, which is perhaps the most important task of radiation safety professionals and it is here where utilitarian ethics finds its role-as it can be seen hereinafter.

There are two different approaches to applying the principle of justification in exposure situations, which depend upon whether or not the source can be directly controlled. The first approach is used in the introduction of new activities where radiological safety is planned in advance and the necessary actions can be taken on the source. Application of the justification principle to these situations requires that no planned exposure situation should be introduced unless it produces sufficient net benefit to the exposed individuals or to society to offset the radiation detriment it causes. Judgments on whether it would be justifiable to introduce or continue particular types of planned situation involving exposure to ionizing radiation are important. The justification may need to be re-examined as new information or technology becomes available.

The second approach is used where exposures can be controlled mainly by action to modify the pathways of exposure and not by acting directly on the source. The main examples are existing exposure situations and emergency exposure situations. In these circumstances, the principle of justification is applied in making the decision as to whether to take action to avert further exposure. Any decision taken to reduce doses, which always have some disadvantages, should be justified in the sense that they should do more good than harm.

In both approaches, the responsibility for judging the justification usually falls on the political branch of the government in general and, arguably, through the ARN in particular, to ensure an overall benefit in the broadest sense to society and thus not necessarily to each individual. However, input to the justification decision may include many aspects that could be informed by users or other organizations or persons outside of the government. As such, justification decisions will often be informed by a process of public consultation, depending upon, among other things, the size of the source concerned. There are many aspects of justification, and different organizations may be involved and responsible. In this context, radiation safety considerations will serve as one input to the broader decision process.

It should be noted that in Argentina, the justification principle has not remained to be a theoretical declarative principle of teleological ethics. The authorities have followed current international radiation safety standards [56] and considered that a number of practices are deemed to be unjustified. For instance, activities are considered unjustified whenever they would result in an increase of radiation doses by deliberate addition of radioactive substances or by activation, in the activity of commodities or products, as well as in food, beverages, cosmetics, or any other commodity or product intended for ingestion, inhalation, or percutaneous intake by, or application to, a human being. Practices involving the frivolous use of radiation or radioactive substances in commodities or products such as toys and personal jewelry or adornments are also deemed to be unjustified. 
Justification of medical exposure of patients is more complex and calls for a different and more detailed approaches. In Argentina, in principle, the medical use of radiation should be justified, as any other planned exposure situation, although that justification lies more often with the medical profession than with regulatory standards. The responsibility for the justification of the use of a particular procedure falls on the relevant medical practitioners rather than on the radiation safety professionals. Justification of medical procedures, however, remains part of the application of teleological ethics to radiation safety and it has been part of the Argentine regulatory practice. For instance, any radiological examination for occupational, legal, or health insurance purposes undertaken without reference to clinical indications is deemed in principle to be unjustified. Moreover, mass screening of population groups involving medical exposure is also in principle deemed to be unjustified. Medical exposure also includes the exposure of humans for medical research and this is deemed to be unjustified unless it is tailored to the provisions of the Helsinki Declaration [57] and specifically follows ethical guidelines such as those from the Council for International Organizations of Medical Sciences and the World Health Organization [58].

At this time of exaggerated emphasis in security, it is proper to recall that international standards establish that radiological examinations for theft detection purposes are deemed to be unjustified.

4.3. Optimization and Utilitarianism. The principle of optimization arises from utilitarian ethics. The optimization process is intended for application to those situations that have been deemed to be justified. Therefore, it is somehow involved in teleological ethics as well. The principle applies to all three exposure situations: planned exposure situations, emergency exposure situations, and existing exposure situations. It is defined by ICRP as the source-related process to keep the likelihood of incurring exposures (where these are not certain to be received), the number of people exposed, and the magnitude of individual doses as low as reasonably achievable, taking economic and societal factors into account.

Safety through utilitarianism can be characterised as a quantitative and reductionist approach to ethics. In general usage, the term utilitarian refers to a somewhat narrow economic or pragmatic viewpoint; however, in Argentina it is considered to be a much broader view that encompasses all aspects of people's lives.

Utilitarians, in contrast to consequentialists, generally hold that the doing certain kinds of safety actions contributes to, or detracts, from, the good not solely in terms of their consequences but also as intrinsically valuable states of affairs in themselves. An example of this is the positing of individual rights not being violated, or duties being kept, as part of the good to be maximized-the so-called "utilitarianism of rights" [59]. This latter position implies that utilitarian approaches to safety shall be constrained with deontological principles. This is the reason why, in Argentine regulations, the principle of optimization includes restriction on the magnitude of individual dose and risk.
The ICRP has earlier provided recommendations on how to apply the optimization principle [7, 60-62], which remain. Some of these recommendations were developed in Argentina [5]. The decision aiding techniques are still essential to find the optimized safety solution in an objective manner. These techniques include methods for quantitative optimization such as cost-benefit analyses. The process of optimization over the past decades has resulted in substantial reductions of occupational and public exposures.

Optimization is always aimed at achieving the best level of safety under the prevailing circumstances through an ongoing, iterative process that involves evaluation of the exposure situation, including any potential exposures (the framing of the process), selection of an appropriate value for dose and risk constraints or reference levels, identification of the possible safety options, selection of the best option under the prevailing circumstances, and implementation of the selected option. Experience has shown how optimization has improved safety. Constraints provide a desired upper bound for the optimization process. Some sources and technologies are able to satisfy constraints that are set at a low level, while others are only able to meet constraints set at a higher level. This is normal and has been reflected in the freedom of regulatory authorities to select values that are appropriate for particular circumstances.

In all situations, the process of optimization with the use of constraints or reference levels is applied in planning protective actions and in establishing the appropriate level of safety under the prevailing circumstances. The doses and risks to be compared with the constraints or reference levels are usually prospective, that is, they may be received or incurred in the future and are not intended as a form of retrospective limit.

Optimization is a forward-looking iterative process that takes into account both technical and socioeconomic developments and requires both qualitative and quantitative judgments. The optimization process is systematic and carefully structured to ensure that all relevant aspects are taken into account. Optimization is a frame of mind, always questioning whether the best has been done in the prevailing circumstances and whether all that is reasonable has been done to reduce doses and risks, requiring commitment at all levels.

The best option is always specific to the exposure situation and represents the best level of safety that can be achieved under the prevailing circumstances. Therefore it is not relevant to determine, a priori, a dose or risk level below which the optimization process should stop. Depending on the exposure situation, the best option could be close to or well below the appropriate source-related constraint or reference level.

In Argentina, optimization is not to be considered a synonym with minimization of dose or risk. Optimization is the result of an evaluation, which carefully balances the detriment from the exposure and the resources available for safety (as opposed to asserting that in every activity we should expend all available resources in the reduction of risk). Thus the best option is not necessarily the one with the lowest dose or risk. In addition to the reduction of the magnitude of 
individual exposures, a reduction of the number of exposed individuals is also considered. The expected collective dose is a key parameter for optimization. The comparison of safety options for the purpose of optimization entails a careful consideration of the characteristics of the individual exposure distribution within an exposed population.

All aspects of optimization are not codified in Argentine regulations because they cannot be. Rather, the Argentine practice is to encourage a commitment by all parties to the optimization process. For the ARN, the focus is not on specific outcomes for a particular situation but rather on processes, procedures, and judgments. An open and qualified dialogue exists between the authority and the operating management, as the success of the optimization process will depend strongly on this dialogue.

Societal values usually influence the final decision on the optimum level of radiation safety. Therefore, some of the Argentine radiation safety requirements can be considered decision-aiding tools, mainly based on scientific considerations, and the Argentine practice is that they serve as an input to a final and usually wider decision-making process, which includes other societal concerns and ethical aspects, as well as considerations of transparency. This decision making process may include the participation of relevant stakeholders rather than radiation safety specialists alone.

4.4. Individual Limitation and Deontology. Deontological ethics impose a duty on individuals, which should be considered inherently good regardless the justification of actions or optimization of safety. The ultimate overall consequences of the safety actions are not important in and of themselves, and the safety intentions are not important in and of themselves. Only the protective act of the individual in itself is important in deontological ethics. However, it is not deontology in extremis but threshold deontology, as the individual norms govern up to a point, a limit, despite adverse consequences; but below such limit utility (optimization) takes over. The moral issue of optimization governing below appropriate individual limits was deeply discussed in the context of radiation safety [18].

Safety based on deontology is ultimately normative regarding which limits are morally required, forbidden, or permitted. In other words, safety deontology falls within the domain of a moral theory that guides and assesses choices of what ought to be done to protect humans. The most traditional mode of classifying deontological safety is to divide it between agent- or source-centred and victim- or individual-centred $[63,64]$.

In the Argentine practice, compliance with the ethical principle of deontology is achieved trough three interrelated concepts: dose and risk constraints, dose and risk reference levels, and dose and risk limits. Dose and risk constraints and dose and risk reference are used for the source-centred (or related) deontological safety. Dose and risk limits are used for the individual-centred (or related) deontological safety. Individual in this respect is defined in Argentina as a representative person for the purpose of protection and safety [65].

In relation to source-centred safety, there are both permissions and obligations that give source-relative reasons for action. Any source-relative reason is an objective reason, but there could be subjective reasons that form the nerve of psychological explanations of some deontological safety actions [66]. A source-relative reason constitutes an objective reason for some particular sources to do or not to do something, even though it need not constitute such a reason for anyone else. Thus, a source-related obligation is an obligation of safety for a particular source. In Argentina, the concepts of dose constraint and reference level are used (in conjunction with optimization) as a source-related deontological restriction on individual doses and risks. The term "constraint" is usually used in planned exposure situations. The term "reference level" is used for existing exposure situations. A level of individual dose or risk, either as a constraint or a reference level, always needs to be defined. The initial intention would be that the source not exceed, or remain at, these levels, and the ambition is to reduce all doses and risk to lower levels (according to the prevailing circumstances) using optimization. The chosen value for a constraint or a reference level will depend upon the circumstances of the exposure under consideration. It must also be realized that neither dose and risk constraints nor reference levels represent a demarcation between "safe" and "dangerous" or reflect a step change in the associated health risk for individuals.

4.4.1. Constraints. The Argentine approach is to consider dose and risk constraints as a prospective and source-related deontological safety restriction on the individual dose and risk from a source in planned exposure situations, which serves as an upper bound on the predicted doses and risks in the optimization of safety for that source. It is a level of dose and risk above which it is unlikely that safety be optimized for a given source of exposure, and for which, therefore, action must almost always be taken. Dose and risk constraints for planned situations represent a basic level of safety and will always be lower than the regulatory limits. During planning it must be ensured that the source concerned does not imply doses and risks exceeding the constraint. Optimization of protection will establish an acceptable level of dose and risks below the constraint. This optimized level then becomes the expected outcome of the planned protective actions.

4.4.2. Reference Levels. The Argentine approach is to consider that reference level of dose and risk represents the level of these quantities, above which there is a deontological judgement that it is inappropriate to plan to allow exposures to occur in emergency or existing controllable exposure situations, and for which therefore protective or safety actions should be planned and optimised. The chosen value for a reference level depends upon the prevailing circumstances of the exposure situation under consideration. When an emergency exposure situation has occurred or an existing exposure situation has been identified and protective actions have been implemented, doses can be assessed. The reference level may then assume a different function as a benchmark against which protection options can be judged retrospectively. The distribution of doses that has resulted from the implementation of a planned protective strategy 
may or may not include exposures above the reference level, depending on the success of the strategy. Efforts should, however, be aimed at reducing any exposures that are above the reference level to a level that is below, whenever possible.

4.4.3. Limits. The Argentine approach is that the individualrelated deontological limit is a value of individuals' committed dose and risk established by the authority which shall not be exceeded in any planned exposure situations. The limits apply to the sum of exposures from sources related to practices that are already justified. As far as dose limits is concerned, the limit for workers is expressed as an effective dose of $20 \mathrm{mSv}$ per year, averaged over defined 5-year periods ( $100 \mathrm{mSv}$ in 5 years), with the further provision that the effective dose should not exceed $50 \mathrm{mSv}$ in any single year. For public exposure in planned exposure situations, the limit is expressed as an effective dose of $1 \mathrm{mSv}$ in a year. However, in special circumstances a higher value of effective dose is allowed in a single year, provided that the average over defined 5-year periods does not exceed $1 \mathrm{mSv}$ per year. The limits on effective dose apply to the sum of doses due to external exposures and committed doses from internal exposures due to intakes of radionuclides. Dose limits do not apply in emergency exposure situations where an informed, exposed individual is engaged in volunteered life-saving actions or is attempting to prevent a catastrophic situation. The risk limits have been set coherently and consistently with these values and are expressed by the criterion curve presented in Figure 1.

4.5. Intergenerational Protection and Virtue Ethics. Arête, in its basic sense, means goodness, excellence, or virtue of any kind and it is bound up with the notion of the fulfillment of purpose or function. Arête in ancient Greek culture was courage and strength in the face of difficult problems, and it included phronesis and eudaimonia. Phronesis provides the basis for the precautionary principle in protection. Eudaimonia represents the common concept of welfare for all, present and future generations, as a result of a protective action. Although, etymologically, the concept derives from the sum of the Greek words " $\varepsilon v\left(\varepsilon \xi_{i} \alpha\right)$ " ("well being") and " $\delta \dot{\alpha} \theta \varepsilon \sigma \eta "$ ("disposition"), and it could be used by extension to mean jocundity and human fortune, it rarely has such connotation; rather, the less subjective "humanity flourishing" is often preferred as a translation.

The Argentine approach to safety recognizes that radiation sources are linked by a variety of interconnected events and situations leading to exposure to doses or risks of individuals, groups, or entire populations, both in the present and in the future. The approach underlines that the doses and risks to be limited are usually prospective, that is, those that may be received in the future, as it is only those that can be influenced by a priori decisions on safety actions. However, the Argentine authorities recognize that both the individual doses and risks and the size of the exposed population become increasingly uncertain as time increases and hold that in the decision making process, owing to the increasing uncertaintie, they give less weight to very low doses and risks that could hypothetically be received in the distant future. This would apply to events in which potential exposures could occur far in the future and the doses and risks would be delivered over long time periods, that is, in the case of solid waste disposal in deep repositories.

The Argentine regulations have implemented the crucial virtue (aeratic) ethical principle of ensuring safety to future generations. It applies to the case of discharges of radioactive materials into the environment. If the discharges occur at a constant rate, the maximum annual per caput dose and risk rates in the future for the specified population will be equal to the dose and risk commitment of one year of practice, namely, to the infinite time integral of the per caput dose and risk rates due to a year of a planned activity causing discharges irrespective of changes in the population size. If the activity causing discharges is continued only over a time period, the maximum future annual per caput dose will be equal to the corresponding truncated dose commitment. Therefore, protection of future individuals is ensured by limiting the infinite time integral of the per caput dose rate due to a year of a planned activity causing discharges

\section{Protection of the Environment}

Argentina has implicitly recognized that anthropocentrism has been de facto at the roots of the evolving ethical thinking on safety. All ethical doctrines focus on the moral behaviour of humans in relation to the safety of other humans. Consequently, those doctrines implicitly regard humankind as the most important element of existence.

Thus, safety-related ethics have been fundamentally anthropocentric. Ethical concerns for the environment are a relatively new phenomenon. Over the last years, however, two fundamental environmental protection approaches (rather than ethics) are being constructed. These are the sotermed biocentrism and ecocentrism, which seem to lack of a fundamental ethical doctrine.

Within an apparent vacuum of environmental protection ethics, ARN is nevertheless closely following the development of some basic principles for protecting not only humans but also the environment from the detrimental effects of radiation exposure. And, as environmental protection is becoming a moral issue, ethical substantiations are being explored.

Recently, under the motto "Not Everything That Is Technically Feasible Is Morally Acceptable" the Bilateral Commission of the Holy See and the Chief Rabbinate of Israel has issued a statement that includes some ethical considerations for the protection of the environment [67]. Recognizing tensions between secular environmentalist movements and religious perspectives, the statement emphasized that "biblical teaching views nature as being endowed with sanctity that flows from the Creator." According to this ethical view, it is the Creator who has charged humanity as the summit of his inherently good Creation (cf. Gen 1:31) with the obligation of responsible custodianship (cf. Gen 2:15). Accordingly while freedom and autonomy are given to humanity to develop and advance the natural resources (Ps 115:16), these must always be expressed in a manner that respects Divine sovereignty 
of the Universe (Ps 24:1); therefore, the essential need for society would be to recognize the transcendent dimension of Creation that is critical to ensure sustainable development and progress in an ethically responsible manner. Thus, the anthropocentric tradition that gives unique dignity to the human person must not be understood in terms of domination but in terms of respect and solidarity, and the ethical aspect of human intervention in the natural order lies in the limitation on the power of science and its claim to absoluteness. These aspects can be reunited from the beginning if nature is considered to mean humankind and environment, the last being considered to mean humankind's habitat.

The ARN also noted that a new feature of the 2007 ICRP Recommendations is that they are concerned with environmental protection as well, rather than only with human protection. The new recommendations depart from previous recommendations in that they were only concerned with the protection of mankind's environment only with regard to the transfer of radionuclides through it. Notwithstanding the new ICRP interest in environmental protection, the ARN continues to be convinced that, in the context of planned exposure situations, the standards of environmental control needed to protect the general public should ensure that other species in the human habitat are not placed at risk. However, the authorities note that the situation could be different in emergency and existing situations and in the environment at large. Thus, authorities in principle adhere to some international basic environmental protection objectives such as: (i) to maintain biological diversity, (ii) to ensure the conservation of species, and (iii) to protect the health and status of natural habitats, communities, and ecosystems, which are based on a framework for assessing the impact of ionizing radiation on nonhuman species that had been issued by ICRP [65].

The issue of environmental protection against radiation had been discussed at the International Conference on Protection of the Environment from the Effects of Ionizing Radiation, which was held in Stockholm in October 2003. At that encounter ARN had expressed scepticism on the challenges to the well-established statement that protecting man automatically implies protection of the environment and their implications on doubts about scientific evaluations [68]. The ARN position was that doubting science in this respect is reasonable (the ARN position was summarized with J. L. Borges dictum "Doubt is a way of naming intelligence"), but, however, in ARN's view, creating pressures and questioning professional institutions by unrepresentative pressure groups and not to responsible guardians of societal interests people does not strength science but rather makes suspicion and mistrust an irrational dominating factor. Moreover, the ARN analysis at the time was that "although there is no scientific evidence of harm to the environment due to justifiedand regulated-practices involving radionuclides, there has been a shift towards concern for the radiation protection of nonhuman species due to changes in societal thinking". ARN was convinced "that the validity of the present system of radiation protection will in due course be demonstrated by the scientific evidence." This scientific evidence is now available, and the ARN position has been corroborated.
It should be recognized that concern for the environment is a recent phenomenon (until recently the word environment itself was absent in the intellectual debate). It will certainly take time to develop comprehensive ethical doctrines that encompass this relatively new human apprehension. The urgent need for an environmental protection ethics is recognized in Argentina [69].

\section{Outcoming Conclusions: The Ethics of Radiation Safety}

From the discussion heretofore, it is obvious that there is a direct correlation between the Argentina's principles of radiation safety and the basic ethical doctrines:

(i) the principle of justification is based on teleological (or consequentialistic) ethics,

(ii) the principle of optimization is based on utilitarian ethics,

(iii) the principle of limitation is based on deontological ethics,

(iv) the principle of protection of intergenerational prudence is based on aretaic (or virtue) ethics.

Distinctly to conventional regulatory approaches, in Argentina these principles are applied to ALL exposure to radiation harm, namely, to exposures to actual doses and to exposures to actual risk and potential doses, including those arising from the safety of nuclear installations. By contrast, most regulatory approaches maintain an artificial division between what is termed radiological safety and nuclear safety.

Moreover, distinctly to conventional ethical approaches, in Argentina all these principles are harmonized and all of them are applied in conjunction. By contrast, conventional ethics (and ethicists) usually emphasize differences among the various ethical approaches and avoid intermixing. Ethicists usually highlight the distinction among the various ethical approaches rather than their synergism. Consequentialists hold that the consequences of a particular protective action form the basis for any valid moral judgment about that action. Utilitarians hold that the maximization of the welfare resulting from a particular protective action forms the basis for any valid moral judgment about that action. Deontologists derive rightness or wrongness from the character of the protective action itself rather than the outcomes. Virtuosity supporters emphasize the character of the moral, rather than consequences, utility or duty, as the key element of ethical safety thinking. However, the difference between the various ethical approaches, in relation to the morality of the safety actions undertaken by humans, tends to lie more in the way the moral dilemmas posed by safety actions are approached than in the conclusions reached.

Building a bridge among all available ethical doctrines and applying it to radiation safety against actual doses and actual risk and potential doses is at the roots of the successful nuclear regulatory experience in Argentina. 


\section{Disclosure}

ARN stands for the Spanish acronym of Autoridad Regulatoria Nuclear of Argentina and also for Argentine Nuclear Regulatory Authority from hereon. ICRP is an independent registered charity, established to advance for the public benefit the science of radiological protection, in particular by providing recommendations and guidance on all aspects of protection against ionizing radiation. Argentina has been a strong supporter of ICRP. The Fundamental Safety Principles were approved in September 2006 [25]. This is the first unified philosophy of nuclear safety and protection against ionizing radiation with a broad international consensus. The Fundamental Safety Principles are jointly sponsored with the European Atomic Energy Community (EURATOM), the Food and Agriculture Organization of the United Nations (FAO), the International Atomic Energy Agency (IAEA), the International Labour Organization (ILO), the International Maritime Organization (IMO), the Nuclear Energy Agency of the OECD (OECD/NEA), the Pan American Health Organization (PAHO), the United Nations Environment Programme (UNEP), and the World Health Organization (WHO).

\section{References}

[1] International Commission on Radiological Protection, ICRP, The 2007 Recommendations of the International Commission on Radiological Protection, ICRP Publication 103. Annals of the ICRP 37(2-4), 2007.

[2] International Atomic Energy Agency, Fundamental Safety Principles: Safety Fundamentals, IAEA Safety Standards Series, no. SF-1, IAEA, Vienna, Austria, 2006.

[3] L. S. Taylor, "The philosophy underlying radiation protection," American Journal of Roentgenology, vol. 77, no. 5, pp. 914-919, 1957.

[4] International Commission on Radiological Protection, Recommendations of the International Commission on Radiological Protection, vol. 9 of ICRP Publication, Pergamon Press, Oxford, UK, 1966.

[5] International Commission on Radiological Protection, Implications of Commission Recommendations that Doses Be Kept As Low As Readily Achievable, vol. 22 of ICRP Publication, Pergamon Press, Oxford, UK, 1973.

[6] International Commission on Radiological Protection, Recommendations of the International Commission on Radiological Protection, vol. 26 of ICRP Publication, 1977, Annals of the ICRP 1 (3).

[7] International Commission on Radiological Protection, Recommendations of the International Commission on Radiological Protection, vol. 60 of ICRP Publication, 1990, Annals of the ICRP 21 (1-3).

[8] B. Lindell, "Radiation and man," in Proceedings of the 3rd Congress of the International Radiation Protection Association, Sievert Lecture. IRPA 3, IRPA, Washington, DC, USA, September 1973.

[9] L. S. Taylor, "Some nonscientific influences on radiation protection standards and practice. The 1980 Sievert lecture," Health Physics, vol. 39, no. 6, pp. 851-874, 1980.

[10] B. Lindell, How Safe is Safe Enough?Lauriston S. Taylor Lectures no.12, National Council on Radiation Protection and Measurements, Bethesda, Md, USA, 1988.
[11] D. Beninson, "Risk of radiation at low doses," in Proceedings of the 9th Congress of the International Radiation Pro-tection Association, Sievert Lecture. IRPA 9, IRPA, Vienna, Austria, April 1996, http://www2000.irpa.net/irpa9/cdrom/VOL.1/ V1_1.PDF.

[12] G. Silini, "Ethical issues in radiation protection-the 1992 Sievert Lecture," Health Physics, vol. 63, no. 2, pp. 139-148, 1992.

[13] L. Persson, Ed., "Ethical issues in radiation protection. An international workshop," SSI-Report 2000:08, Stockholm, Sweden, 2000.

[14] B. Lindell, Pandoras Ask, Atlantis, Stockholm, Sweden, 1996.

[15] B. Lindell, Damokles Svärd, Atlantis, Stockholm, Sweden, 1999.

[16] B. Lindell, Herkules Storverk, Atlantis, Stockholm, Sweden, 2003.

[17] Science and Values in Radiological Protection Workshop (In-depth discussions of how science and social values are taken into account in the formation of policy and regulatory judgements took place at a workshop, Finland, January) NEA Annual Report 2008; Nuclear Energy Agency; Organisation for Economic Co-operation and Development; Science and Values in Radiological Protection workshop, Helsinki, Finland, January 2008, Radiation and Nuclear Safety Authority of Finland (STUK), 2008.

[18] "Science and Values in Radiological Protection," in Proceedings of the 2nd Workshop of the CRPPH on Radiological Protection and Public Health, Vaulx de Cernay, France, November-December 2009, http://www.nea.fr/html/rp/vaulx_de_cernay09/ welcome.html.

[19] R. Clarke, "Control of low-level radiation exposure: time for a change?" Journal of Radiological Protection, vol. 19, no. 2, pp. 107-115, 1999.

[20] R. H. Clarke, "Progress towards new recommendations from the International Commission on Radiological Protection," Nuclear Energy, vol. 40, no. 1, pp. 37-45, 2001.

[21] R. H. Clarke, "International aspects of radiological protection," Nuclear Energy, vol. 42, no. 2, pp. 83-86, 2003.

[22] G. Eggermont, Ed., Ethics and Radiological Protection, vol. 3 of Collection Science, Ethique et Société, Academia Bruylant, Louvain-La-Neuve, Belgium, 2008.

[23] NORMA AR 10.1.1, "Normas Básicas de Seguridad Radiológica," Autoridad Regulatoria Nuclear, Buenos Aires, Argentina, 2010, http://http://www.arn.gob.ar/normas/10-1-1R3 .pdf.

[24] NORMA AR 3.1.3, "Criterios Radiológicos Relativos a Accidentes en Reactores Nucleares de Potencia," Autoridad Regulatoria Nuclear, Buenos Aires, Argentina, 2010, http:// www.arn.gob.ar/normas/3-1-3R2.pdf.

[25] "Joint convention on the safety of spent fuel management and on the safety of radioactive waste management," Tech. Rep. INFCIRC/546, IAEA, Vienna, Austria, 1997.

[26] Radiation Protection Convention, 1960 (no. 115); General Conference of the International Labour Organisation, 44th Session, June 1960; The International Labour Office, Geneva, Switzerland, 1960. (See also: Radiation protection of workers [ILO, 1987]. International Labour Organization. (Ionising radiations)-An ILO Code of Practice. The International Labour Office, Geneva, Switzerland, 1987.

[27] A. J. Gonzalez, "Un criterio para la evaluacion de la seguridad nuclear," in Proceedings of Symposium on Siting of Nuclear Facilities, Jointly Organized by the International Atomic Energy Agency and the OECD Nuclear Energy Agency, pp. 265-281, Vienna, Austria, December 1974. 
[28] Comisión Nacional De Energía Atómica, Buenos Aires. (Argentina). Consejo Asesor para el Licenciamiento de Instalaciones Nucleares. "Criterios radiológicos relativos a accidentes". Buenos Aires, CNEA, 1979. 2 p. NORMA CALIN N ${ }^{\circ}$ 3.1.3.

[29] Comisión Nacional De Energía Atómica, Buenos Aires. (Argentina). Consejo Asesor para el Licenciamiento de Instalaciones Nucleares. "Análisis de falias para la evaluacion de riesgos". Buenos Aires, CNEA, 1980. 1 p. NORMA CALIN N ${ }^{\circ}$ 3.2.2.

[30] A. J. González, "The regulatory use of probabilistic safety analysis in Argentina," in International Meeting on Thermal Reactor Safety, vol. 1, Chicago, Ill, USA, August-September 1982.

[31] A. J. González, "The regulatory use of probabilistic safety analysis in Argentina," in Technical Committee on Status, Experience and Future Prospects for the Development of Probablisitic Safety Criteria, IAEA, Vienna, Austria, January 1986.

[32] Comisión Nacional De Energía Atómica, Buenos Aires. (Argentina) Consejo Asesor para el Licenciamiento de Instalaciones Nucleares. "Limitación de efluentes radiactivos" Buenos Aires, CNEA, 1974. 2 p. NORMA CALIN N 3.1.2.

[33] D. J. Beninson and A. J. González, "Optimization of nuclear safety systems," in Proceedings of the International Conference on Current Nuclear Power Plants Safety Issues Organized by the International Atomic Energy Agency, vol. 2, pp. 449-456, IAEA, Stockholm, Sweden, October 1980, IAEA-CN39/211 STI/PUB/566.

[34] D. J. Beninson and B. Lindell, "Critical views on the application of some methods for evaluation of accidents probabilities and consequences," in Proceedings of an International Conference on Current Nuclear Power Plants Safety Issues organized by the International Atomic Energy Agency, vol. 2, pp. 325-341, IAEA, Vienna, Austria, October 1980.

[35] Gobierno de la República Argentina; Ley 25.188, "Ley de Ética de la Función Pública," y sus normas modificatorias, 2010, http://www.ddjjonline.gov.ar/ley25188.doc.

[36] "Código de Ética de la Autoridad Regulatoria Nuclear," Autoridad Regulatoria Nuclear, Buenos Aires, Argentina, 2010, http://www.arn.gob.ar/Calidad/Revisi\%F3n4C\%F3d\%C9tica .pdf.

[37] Interantional Radiation Protection Association, in IRPA Congress for Central and Eastern Europe, Brasov, Romania, September 2007, http://www.irpa.net/index.php?option= com_content\&view=article\&id=71\&Itemid=174.

[38] "Ethical considerations in protecting the environment from the effects of ionizing radiation," Tech. Rep. IAEA-TECDOC1270, IAEA, Vienna, Austria, 2002.

[39] "Protection of the environment from the effects of ionizing radiation," in Proceedings of an International Conference on Protection of the Environment from the Effects of Ionizing, IAEA Proceedings Series, IAEA, Stockholm, Sweden, October 2003.

[40] Establishing a Code of Ethics for Nuclear Operating Organizations, IAEA Nuclear Energy Series, no. NG-T-1.2, IAEA, Vienna, Austria, 2008.

[41] M. Nicolò, (Written c. 1505, published 1515, translated by W. K. Marriott 1908), http://www.constitution.org/mac/prince00 .htm.

[42] J. Bentham, An Introduction to the Principles of Morals and Legislation, vol. 1789, Adamant Media Corporation, Latest edition, 2005.

[43] J. S. Mill, Bentham, Dissertations and Discussion, Westminster Review, London, UK, August 1838.
[44] C. D. Broad, Five Types of Ethical Theory, Harcourt, Brace, New York, NY, USA, 1930.

[45] I. Kant and J. Ladd, The Metaphysical Elements of Justice; Part I of the Metaphysics of Morals, Hackett, Indianapolis, Ind, USA, 1965.

[46] M. Moore, Placing Blame: A General Theory of the Criminal Law, Oxford University Press, Oxford, UK, 1997.

[47] E. Wierenga, "A defensible divine Ccommand theory," Noûs, vol. 17, no. 3, pp. 387-407, 1983.

[48] C. Swanton, Virtue Ethics: A Pluralistic View, Oxford University Press, Oxford, UK, 2003.

[49] Anscombe, Modern Moral Philosophy, 1983, The 41st World Medical Assembly, Hong Kong, 1989.

[50] R. Crisp and M. Slote, Virtue Ethics, Oxford University Press, Oxford, UK, 1997.

[51] S. Darwall, Ed., Virtue Ethics, B. Blackwell, Oxford, UK, 2003.

[52] R. J. Devettere, Introduction to Virtue Ethics, Georgetown University Press, Washington, DC, USA, 2002.

[53] S. M. Gardiner, Ed., Virtue Ethics, Old and New, Cornell University Press, Ithaca, NY, USA, 2005.

[54] R. Hursthouse, On Virtue Ethics, Oxford University Press, Oxford, UK, 2001.

[55] R. Taylor, An Introduction to Virtue Ethics, Prometheus Books, Amherst, Mass, USA, 2002.

[56] International Atomic Energy Agency, IAEA, International Basic Safety Standards for Protection against Ionizing Radiation and for the Safety of Radiation Sources, Safety Series no. 115, IAEA, Vienna, Austria, 2006.

[57] Helsinki Declaration. Adopted by the 18th World Medical Assembly, Helsinki, Finland, 1964.

[58] Council For International Organizations Of Medical Sciences (CIOMS), International Ethical Guidelines for Biomedical Research Involving Human Subjects, Prepared by the CIOMS in Collaboration with the World Health Organization (WHO), Geneva, Switzerland, 2002, http://www.fhi.org/training/fr/ retc/pdf_files/cioms.pdf.

[59] R. Nozick, Anarchy, State and Utopia, Basic Books, New York, NY, USA, 1974.

[60] International Commission on Radiological Protection, "Assessing dose of the representative person for the purpose of radiation protection of the public," Annals of the ICRP, vol. 36, no. 3, 2006.

[61] International Commission on Radiological Protection, ICRP, Cost-Benefit Analysis in the Optimization of Radiation Protection, ICRP Publication 37. Annals of the ICRP 10 (2-3), 1980.

[62] International Commission on Radiological Protection, Optimization and Decision Making in Radiological Protection, ICRP Publication 55. Annals of the ICRP 20 (1), 1990.

[63] "Introduction," in Consequentialism and Its Critics, S. Scheffler, Ed., Oxford University Press, Oxford, UK, 1988.

[64] F. M. Kamm, Intricate Ethics: Rights, Responsibilities, and Permissible Harms, Oxford University Press, Oxford, UK, 2007.

[65] International Commission on Radiological Protection, A framework for assessing the impact of ionising radiation on non-human species, vol. 91 of ICRP Publication, 2003, Annals of the ICRP 33 (3).

[66] T. Nagel, The View from Nowhere, Oxford University Press, New York, NY, USA, 1986.

[67] Catholic-Jewish Commission, "Statement Upon the Conclusion of the Bilateral Commission of the Holy See and the Chief Rabbinate of Israel," Vatican City, Italy, January 2010, http://www.zenit.org/article-28102?l=english. 
[68] "Regulatory control of discharges of radioactive material to the environment: a regulator's view," in Proceedings of the International Conference on Protection of the Environment from the Effects of Ionizing Radiation, IAEA, Vienna, Austria, October 2003.

[69] G. Arnaud, "Por una ética ambiental," in Anales de la Academia Nacional de Geografía, pp. 79-85, Buenos Aires, Argentina, 2009. 

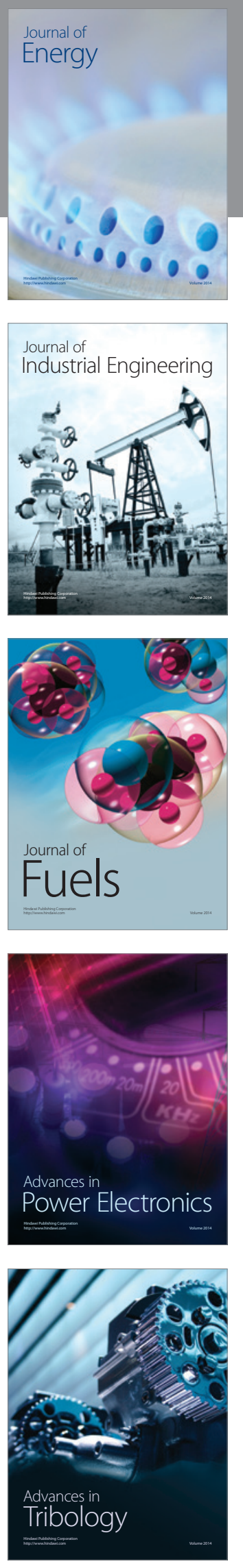
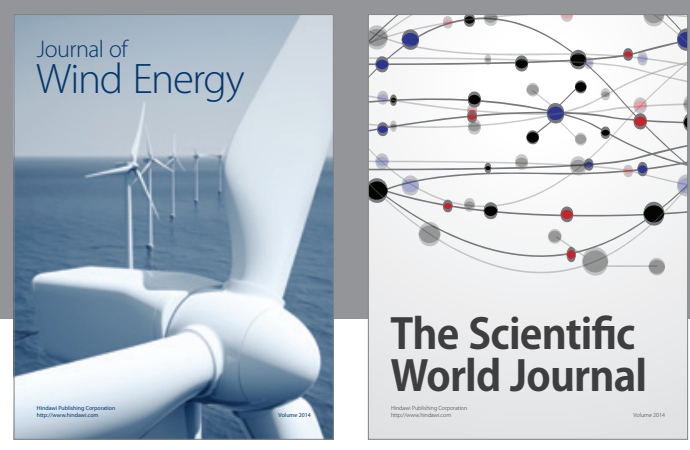

The Scientific World Journal

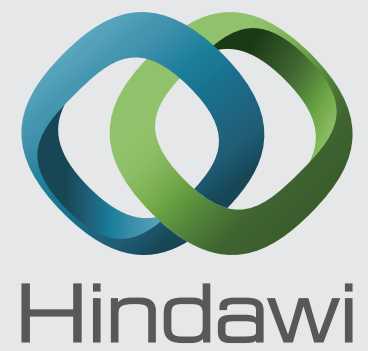

Submit your manuscripts at http://www.hindawi.com
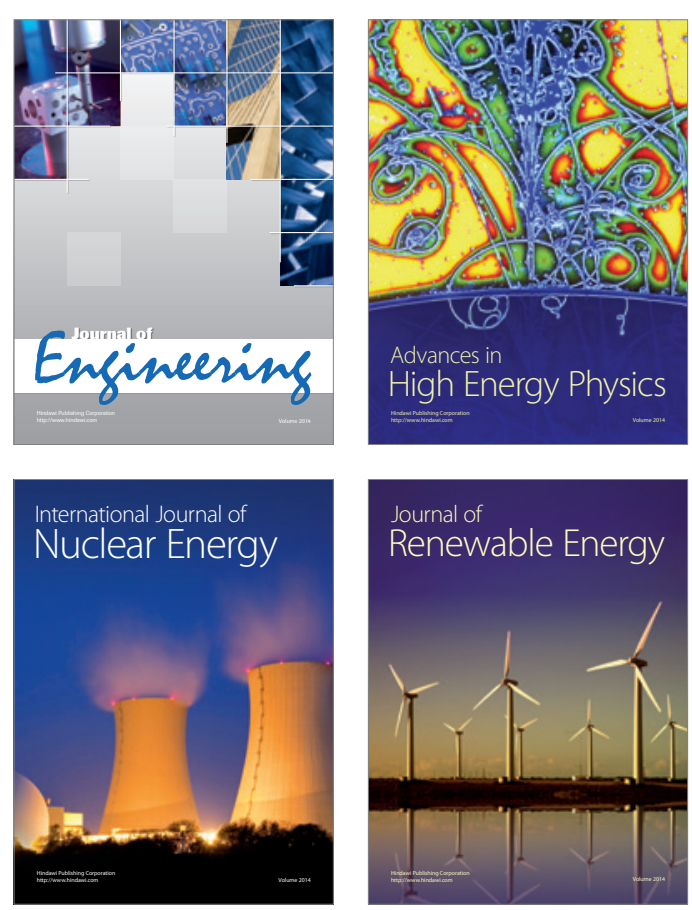

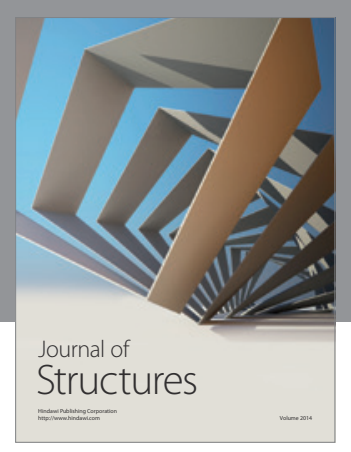

Rotating
Mechinery
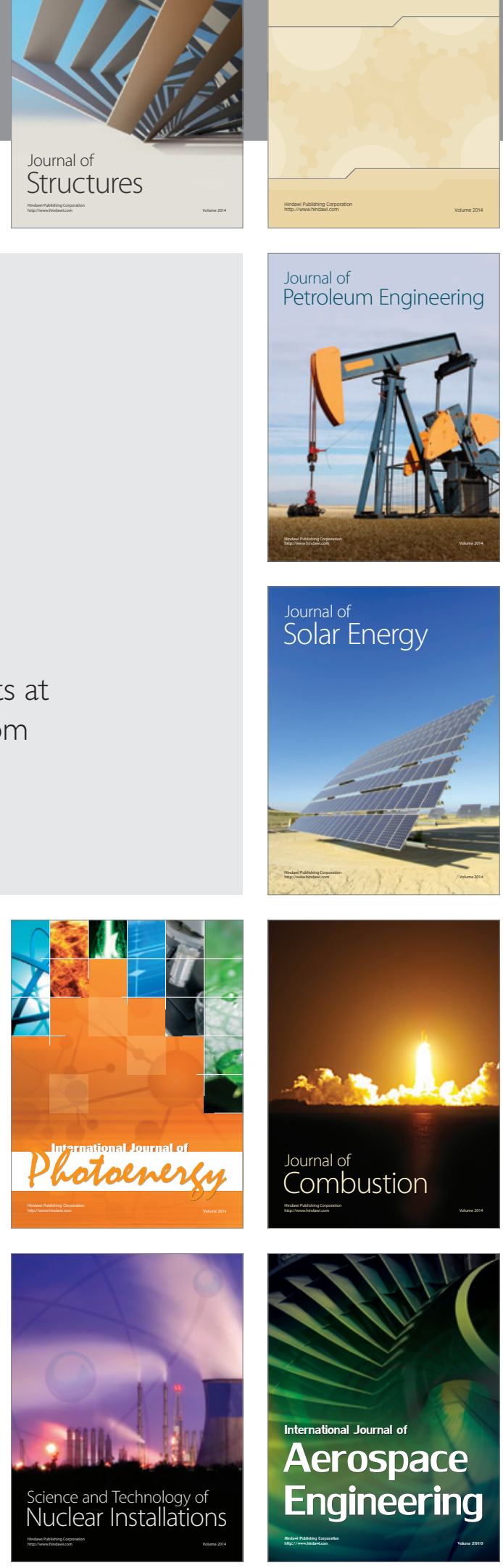